\title{
Teachers' Perceptions of the Transition from Onsite to Online Teaching during the Covid-19 Pandemic
}

\author{
Luu Nguyen Quoc Hung \\ Can Tho University, Vietnam. \\ Email:nghung@ctu.edu.vn
}

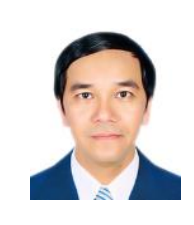

\begin{abstract}
Educational systems worldwide have been affected by government restrictions imposed in response to the Covid-19 pandemic, causing the temporary closure of many educational institutions. The new condition has forced teachers to make the transition from onsite to online teaching. The current study used a descriptive method to examine online teachers' perceptions towards online teaching during the transition to online learning at a center for foreign languages in Vietnam. The results reveal that teachers have a relatively positive perception of online teaching, although many typical problems of online teaching do present themselves and the effectiveness of online teaching does not always compare favorably with traditional classroom teaching. Teachers' suggestions are significant for improving online teaching quality. Online teaching is highly likely here to stay and will continue to improve. The transition from traditional face-to-face classrooms to online teaching can be successfully achieved and its quality can be ensured if challenges and ways of improving online learning continue to be closely examined.
\end{abstract}

Keywords: Covid-19, Online teaching, Perceptions, Quality, Problems, Transition.

Citation | Luu Nguyen Quoc Hung (2021). Teachers' Perceptions of the Transition from Onsite to Online Teaching during the Covid19 Pandemic. Journal of Education and e-Learning Research, 8(4):

416-422.

History:

Received: 4 October 2021

Revised: 9 November 2021

Accepted: 2 December 2021

Published: 20 December 2021

Licensed: This work is licensed under a Creative Commons

Attribution 3.0 License (c) Er

Publisher: Asian Online Journal Publishing Group
Funding: This study received no specific financial support.

Competing Interests: The author declares that there are no conflicts of interests regarding the publication of this paper.

Transparency: The author confirms that the manuscript is an honest, accurate, and transparent account of the study was reported; that no vital features of the study have been omitted; and that any discrepancies from the study as planned have been explained.

Ethical: This study follows all ethical practices during writing.

\section{Contents}

1. Introduction 417

2. Literature Review

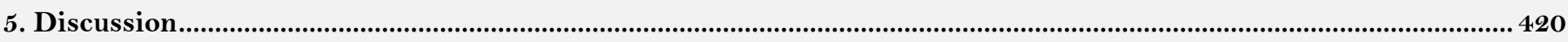

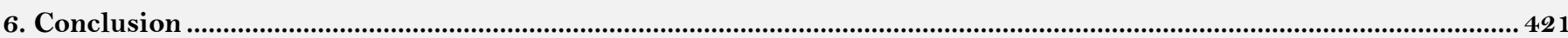

References 


\section{Contribution of this paper to the literature}

This study contributes to existing literature by using a descriptive method in order to examine online teachers' perceptions towards online teaching during the transition to online learning at a center for foreign languages in Vietnam.

\section{Introduction}

The Covid-19 pandemic has presented most educational institutions with the challenge of converting face-toface instruction to online teaching and learning. For many teachers who were trained to work in physical classrooms, this was a completely new paradigm. Online teaching is challenging because teachers are faced with new problems, such as facilities, technology literacy, online class management, and teaching methods in the online environment. At the Center of Foreign Languages at Can Tho University in Vietnam, online teaching and learning is still in its infancy. It has been expanding recently, particularly since the Covid-19 pandemic when the closure of all schools forced teachers to turn to online teaching. Many teachers experienced difficulties in the transition to online teaching. One fundamental problem was that not many teachers had sufficient experience to conduct online courses in response to the sudden shift to online teaching. A thorough understanding of teachers' perceptions is required in order to guarantee that online teaching and learning is implemented successfully. While most studies of online teaching during the Covid-19 pandemic have centered on university settings, few studies have so far been conducted in the context of foreign language centers, especially in the Vietnamese context. A study examining teachers' perceptions towards online teaching is necessary, not only for teachers but also for educational institutions to make appropriate adjustments to enhance the quality of online teaching.

\section{Literature Review}

\subsection{Online Teaching and Its Comparison with Onsite Teaching}

Online teaching generally refers to any kind of teaching and learning via an internet connection rather than in person. Online English teaching has seen an incredible growth in popularity in recent years, especially in the past few years due to the Covid-19 pandemic, which leads to the necessity of considering the differences between online learning and the traditional classroom. A traditional classroom involves a standard curriculum delivered by a teacher in person. Classroom learning helps learners and teachers get to know each other better. This generally allows teachers to better evaluate the learners' strengths and weaknesses. In a traditional classroom, learners can directly share their views and clarify their queries with the teacher, thus getting their questions answered immediately (Alsaaty, Carter, Abrahams, \& Alshameri, 2016).

When we think of learning online, live online lessons such as Zoom meeting sessions are in some ways similar to traditional face-to-face classes in which a teacher presents lessons and interacts with learners in real time. However, there are still several major differences between these modes of teaching and learning. The major difference is classroom management (Lathifah, Helmanto, \& Maryani, 2020). In a physical classroom, the teacher can freely move the learners around, grouping them in different ways to organize different activities. Most online classes use conferencing software that allows for the use of breakout rooms and different arrangements of learners in the classroom. However, in reality, the most effective way to conduct online lessons is for the teacher or presenter to manage the group as a whole. Because of this, online classes are more effective when they are limited to a smaller number of learners.

In online classes, a lack of visual feedback is a common challenge for teachers. It is important that when teaching in a physical classroom, teachers are able to adapt their delivery depending on the immediate visual feedback they perceive, such as the learners' facial expressions. In the online classroom, it is more difficult to get similar feedback. Furthermore, distractions in online classes are more common and challenging. Posing regular questions to learners, which they can respond to with voting tools, can be a useful way to check their engagement in a synchronous online session. In an online teaching and learning environment, different feedback practices are usually implemented to keep learners engaged with the learning material (Jensen, Bearman, \& Boud, 2021).

Technical involvement is another main difference of online teaching. In traditional learning, learners also need basic technical skills for documentation and for collecting data from the internet. In both traditional and online learning, technical skills are necessary, but the demands of online learning are greater. To do well in online courses, learners must necessarily have basic computer literacy. Likewise, teachers must be able to incorporate different resources into lessons, and make the lessons more engaging using various media, including web pages, software programs, search engines, and social media (Winter, Costello, O’Brien, \& Hickey, 2021).

\subsection{Effectiveness of Onsite and Online Learning}

Effective classrooms, whether onsite or online, can be measured on some main aspects relating to course content, pedagogical approaches, interactivity and assessment (Darkwa \& Antwi, 2021). Course content is an essential element of every school curriculum that needs much attention. Generally speaking, content is what teachers teach. The teacher in a classroom is expected to have a broad and current understanding of the subject matter's major content areas. Every teacher's aim in the teaching and learning environment is to deliver a lesson to the learners' satisfaction. For learners to fully understand a lesson, the lesson's content should be presented clearly to facilitate their understanding of it. Also, the lesson should involve a series of activities that involve the students in the lesson through class participation. Activity-oriented lessons can enhance learners' understanding of content through practice.

Pedagogical approaches are the various strategies and skills teachers employ in the classroom to help students achieve learning outcomes and realize their full educational potential. Learners in the modern language classroom often learn through techniques drawn from a variety of methods or approaches in what has been labelled an 'eclectic approach'. Teachers can generally select techniques from various approaches according to the different needs of their learners (Suleman \& Hussain, 2016). While traditional approaches such as the communicative 
approach are still useful for effective language teaching, it is important to explore and implement new teaching strategies such as the use of smart phones in the new learning environment.

Interactions among learners, and between teachers and learners, are essential to effective classroom learning. Both online learning and classroom learning require learners and teachers to interact in the teaching and learning process. All learners crave interaction, whether in face-to-face settings or online environments, and research shows that interaction can increase learning (Weizheng, 2019). While opportunities for interaction may occur without much planning in a face-to-face environment, designing and implementing interactive learning experiences online generally requires more strategic planning to increase interactions between teachers and learners and among learners.

Assessment is an integral part of both traditional and online education to determine learners' achievement of learning outcomes. Teachers use assessment to obtain information they need to make decisions about learners, the curriculum, and educational policy. In an online learning environment, both formative and summative assessment practices require an understanding of the features and tools inherent to the electronic medium (Baldwin \& Trespalacios, 2017).

\subsection{Online Teaching and Learning during the Covid-19 Pandemic in Vietnam}

Due to the widespread Covid-19 pandemic and the implementation of social distancing across the country, most educational institutions in Vietnam shifted to online education within a short time period, independent of whether teachers were prepared for the change (Pham \& Ho, 2020). In fact, online teaching has been proposed for years, but has received very little enthusiasm from universities, teachers and students. It was not until the outbreak of Covid-19 that the Vietnamese government and universities had no choice but to conceive a plan for online education. Vietnam has been slow to take up online teaching, but the Covid-19 pandemic has provided Vietnam with a great opportunity to review its online training capacity and potential, particularly regarding its national policies and legal framework, its ICT infrastructure, and higher education institutions' online teaching capacity. In the context of Covid-19, it appears that online learning has been widely welcomed and accepted both within educational institutions and in the wider community. The actions of stakeholders at different levels are building a firm foundation for the sector to develop further in the near future (Ho, 2021).

\section{Methodology}

\subsection{Research Setting: CFL and its Online Programs}

The Center of Foreign Languages, Can Tho University, Vietnam (hereafter referred to as "the Center" or CFL), provides different varieties of fee-paid courses in foreign languages, such as English, French, Chinese, Japanese and Korean, and the online program makes up a small part of different programs at the Center. In response to the Covid-19 pandemic and the country's period of social distancing, the Center shifted to online teaching and learning in early May of 2021 and began to offer more online classes. Currently, there are three groups of learners in online programs: One group for exam preparation such as for the IELTS, TOEIC or VSTEP (Vietnamese Standardized Test of English Proficiency), one for General English for adults, and the last is General English for young learners. The class size is relatively small, between 15 and 24 learners. The teachers generally use Zoom meetings as the technical tool of instruction. The course duration is between 8 and 10 weeks, and each class has 2 or 3 Zoom sessions per week.

With the shift to online teaching, the Center has adjusted the course content of all its programs, reorganized the syllabi, trained teachers in online pedagogical approaches, and, most practically, prepared the necessary technological facilities, such as Internet connectivity and Zoom service licenses to conduct online classes. As in traditional classrooms, the role of the online teacher is vital to the success of the program. Teachers' perceptions of this new mode of online teaching, after switching from onsite to online teaching, is worthy of consideration (Scherer, Howard, Tondeur, \& Siddiq, 2021).

\subsection{Research Design}

In this study, a descriptive survey design was employed, in which questionnaires were distributed to all the current online teachers at the Center. Questionnaires are considered a low-cost research tool that can help to collect data from a large number of respondents in a short period of time (Gay, Mills, \& Airasian, 2012). A questionnaire based on a review of previous online learning literature is appropriate in this study because of the feasibility of delivering it, gathering responses, and producing reliable data.

\subsection{Participants}

The survey was handed out to all online teachers at the Center. Of the 49 possible respondents, 34 (69.39\%) completed the questionnaire. The basic characteristics of the participants are shown in Table 1.

Table-1. Demographic characteristics of participants ( $\mathrm{N}=34)$.

\begin{tabular}{l|c|c}
\hline Characteristics & Number & Percentage \\
\hline Gender & \multicolumn{2}{|l}{} \\
\hline Female & 26 & $76.5 \%$ \\
\hline Male & 8 & $23.5 \%$ \\
\hline Online teaching experience & 3 & $8.8 \%$ \\
\hline No experience & 17 & $50.0 \%$ \\
\hline 1-2 years & 9 & $26.5 \%$ \\
\hline 3-5 years & 5 & $14.7 \%$ \\
\hline More than 5 years & & \\
\hline
\end{tabular}




\subsection{Instrument}

The teaching staff were invited to respond to an online questionnaire. There were three main sections. In the first section, the participants were asked to rank the level of seriousness of various typical problems of online teaching, using a five-point Likert-scale ranging from 0 (not serious at all) to 4 (very serious). The second section asked the participants to compare the effectiveness of online versus onsite teaching using a scale ranging from 0 (much less effective) to 4 (much more effective). The last section had one open question, asking the participants to provide their suggestions for improving online teaching.

\section{Results}

The results and discussion are presented based on a detailed analysis of the data resulting from the three parts of the questionnaire.

\subsection{Teacher's Problems with Online Teaching}

Teaching online classes is a great challenge for many teachers who have been in the habit of conducting classroom teaching over many years. Teachers have to overcome many challenges to accomplish the objective of teaching and learning. In this study, the teachers were asked to rate the level of seriousness of common problems in online teaching. Overall, the average mean scores were around the medium level, as shown in Table 2. The fifteen problems have been ranked according to their mean scores. The highest mean score was 2.85 for the problem "maintaining learners' motivation and engagement" and the lowest mean score was 2.12 for the problem "teacher's access to technology". It is also interesting to note that the difference between the highest mean score and the lowest mean score was relatively small, less than 1 score value.

\begin{tabular}{|c|c|c|c|c|c|c|c|c|}
\hline \multirow[t]{2}{*}{ Problems } & \multirow[t]{2}{*}{ Mean } & \multirow[t]{2}{*}{ SD } & \multicolumn{5}{|c|}{ Scale } & \multirow[t]{2}{*}{$\overline{\text { Rank }}$} \\
\hline & & & $\mathbf{0}$ & 1 & 2 & 3 & 4 & \\
\hline - Maintaining learners' motivation and engagement & 2.85 & 1.184 & 1 & 5 & 5 & 10 & 13 & 1 \\
\hline - $\quad$ Learners' access to technology & 2.62 & 1.206 & 2 & 4 & 9 & 9 & 10 & 2 \\
\hline - $\quad$ Time spent preparing for online lessons & 2.59 & 1.351 & 2 & 8 & 4 & 8 & 12 & 3 \\
\hline - $\quad$ Dealing with technical issues & 2.59 & 1.328 & 2 & 8 & 3 & 10 & 11 & 3 \\
\hline - Designing engaging activities & 2.53 & 1.308 & 3 & 5 & 7 & 9 & 10 & 5 \\
\hline - Arranging online tests/exams & 2.53 & 1.308 & 3 & 6 & 4 & 12 & 9 & 5 \\
\hline - $\quad$ Time spent communicating with learners & 2.47 & 1.419 & 6 & 1 & 8 & 9 & 10 & 7 \\
\hline - Interaction with learners & 2.47 & 1.331 & 3 & 6 & 7 & 8 & 10 & 7 \\
\hline - $\quad$ Time spent checking assignments & 2.41 & 1.209 & 1 & 9 & 7 & 9 & 8 & 9 \\
\hline - $\quad$ Learners submitting assignments & 2.38 & 1.129 & 1 & 8 & 8 & 11 & 6 & 10 \\
\hline - $\quad$ Learners' understanding of content & 2.35 & 1.368 & 4 & 6 & 7 & 8 & 9 & 11 \\
\hline - Learner absence / retention & 2.29 & 1.194 & 2 & 7 & 11 & 7 & 7 & 12 \\
\hline - $\quad$ Time spent teaching & 2.21 & 1.388 & 6 & 5 & 5 & 12 & 6 & 13 \\
\hline - Teacher's pedagogical digital competence & 2.21 & 1.388 & 5 & 7 & 5 & 10 & 7 & 13 \\
\hline - Teacher's access to technology & 2.12 & 1.431 & 5 & 9 & 5 & 7 & 8 & 15 \\
\hline
\end{tabular}

The respondents view the problem of "maintaining learners' motivation and engagement" as the most serious problem in online teaching. The result is relatively in line with previous literature (Chiu, Lin, \& Lonka, 2021), indicating that increasing learners' engagement and motivation is generally a key challenge in the online learning process.

The second ranked problem was "learners' access to technology" with a mean score of 2.62. The result is in accordance with a statistical report (Statista, 2020) that showed that in $202037.9 \%$ of Vietnamese children encountered technical problems when joining online classes during the Covid-19 pandemic.

The problem of "interaction with learners" was in the middle of the rank. The result is relatively unexpected, because most previous literature generally emphasizes the challenge of increasing learner interaction in an online environment (Efriana, 2021).

The problem of learner retention was not perceived as being very serious in this study, with a mean score of 2.29. The result is somewhat different from a recent report (Bawa, 2016) that indicated that a low retention rate is still a critical concern for many online courses and programs.

The lowest-ranked problem was "teacher's access to technology". Although the level of seriousness of this problem was not high for the respondents in this study, this technological barrier generally poses a great challenge for teachers who were primarily trained to teach face-to-face (Albrahim, 2020).

\subsection{Effectiveness of Onsite and Online Teaching}

The effectiveness of online teaching, when compared with onsite teaching, is still a constant debate in the extensive literature on the subject (Elfaki, Abdulraheem, \& Abdulrahim, 2019; Rachmah, 2020). In this study, it is worth noting that the participants perceived online teaching to be equally effective with traditional classrooms in the two aspects of course content and assessment, as presented in Table 3.

With regard to pedagogical approaches, $47.1 \%$ of the teachers in this study perceived online teaching as being equally effective as regular onsite classes. As expected, interactivity is a significant challenge in online teaching; $41.2 \%$ of the participants indicated that online teaching was somewhat less effective than onsite teaching in this regard. Concerning learners' performance, only ten teachers $(29.4 \%)$ in the study perceived online teaching as being equally effective, and fully half of the participants considered learners' performance to be less effective in online classrooms than in the physical classroom. 
Table-3. Comparison of effectiveness of online teaching versus onsite teaching $(\mathrm{N}=34)$.

\begin{tabular}{l|c|c|c|c|c}
\hline Aspects & $\begin{array}{c}\text { Much less } \\
\text { effective }\end{array}$ & $\begin{array}{c}\text { Somewhat } \\
\text { less effective }\end{array}$ & $\begin{array}{c}\text { Equally } \\
\text { effective }\end{array}$ & $\begin{array}{c}\text { Somewhat more } \\
\text { effective }\end{array}$ & $\begin{array}{c}\text { Much more } \\
\text { effective }\end{array}$ \\
\hline Course content & & $\begin{array}{c}8 \\
(23.5 \%)\end{array}$ & $\begin{array}{c}17 \\
(50 \%)\end{array}$ & $\begin{array}{c}6 \\
(17.7 \%)\end{array}$ & $\begin{array}{c}3 \\
(8.8 \%)\end{array}$ \\
\hline Pedagogical approaches & 1 & 9 & 16 & 3 \\
$(47.1 \%)$ & $(8.8 \%)$ & 5 \\
& $(2.9 \%)$ & $(26.5 \%)$ & $14.7 \%)$ \\
\hline Interactivity & $(5.9 \%)$ & $(41.2 \%)$ & $(29.4 \%)$ & $(8.8 \%)$ & $(14.7 \%)$ \\
\hline Assessment & & 9 & 17 & 2 & 6 \\
& 1 & $(26.5 \%)$ & $(50 \%)$ & $(5.9 \%)$ & $(17.6 \%)$ \\
\hline Learners' performance & $(2.9 \%)$ & $(47.1 \%)$ & $(29.4 \%)$ & $(8.8 \%)$ & 4 \\
& & & & $(11.8 \%)$ \\
\hline
\end{tabular}

\subsection{Suggestions}

Participants were finally invited to suggest ways to improve online teaching. It is interesting to note that over $20 \%$ of the teachers reported their satisfaction with online teaching and had no specific suggestions to make. Of the offered suggestions, most focus on the necessity of training teachers for online teaching, the effectiveness of creating engaging online activities, the availability of teaching tools, technical support, class schedules, and the appropriate class size.

The success of the online learning process greatly depends on the ability of teachers to communicate and use online skills. Online teachers generally need additional training in multiple areas in order to best support the teaching and learning process. In this study, most of the participants indicated a desire for immediate and informal workshops or practical training that would share tips and techniques for online teaching.

I hope that I can take part in information technology training sessions so that I can learn new tools or methods for online

teaching from teachers and my colleagues.

I think the Center should conduct more workshops and meetings to share technology tips and class management techniques.

Engaging students in the learning process can increase their attention and focus, and, consequently, can promote meaningful learning experiences and increase academic performance. In the online learning process, due to its isolated environment, it is essential to create activities that enhance engagement. These activities assist learners in feeling connected and can create a dynamic sense of learning community. In the current study, the participants suggested that varying activities can be an effective way to mitigate fatigue and make learning more engaging for online learners.

It would be a good idea if the teacher can apply a variety of in-class activities in an online lesson including songs, games, video clips, storytelling, asking and answering, role-plays, group work, acting as a model ...

Apart from having a well-prepared lesson plan, I personally think teachers should be able to create different activities for active learning.

Teachers in this study suggested the need to use various available tools to help instructors become more proficient so they can meet learning objectives and increase learners' performance.

I hope that there will be more effective online learning tools to help learners interact with their teachers and friends.

Teachers should use more online teaching tools. In addition, teachers should be more flexible in creating interactions with learners in the teaching process.

For teachers, the availability of assistance and support in using technology is very necessary to ensure that they have the necessary resources and skills for effective teaching.

Teachers should be trained and provided with more technical support.

The internet connection must be stable. We need 24/7 support to be available.

Another theme within the participants' suggestions concerns the adjustment of the lesson length. For effective lesson presentations in synchronous meetings, most of the teachers suggested a shorter duration for online classes in comparison with traditional classrooms. As suggested by several online experts, a good length for an online session is under thirty minutes.

For effective teaching and learning, particularly in teaching young learners, several participants suggested having a more appropriate class size. As suggested in the previous literature (Orellana, 2006) an effective online class size numbers between 12 and 15 learners.

\section{Discussion}

The Covid-19 pandemic has brought a radical change to the country's educational system, necessitating a shift of the teaching and learning process from face-to-face interaction in the classroom to a virtual classroom environment. This shift has created challenges for many parties, including teachers as the main agent in the classroom. For some teachers, conducting online classes is in itself a great challenge because they have been used to conducting classroom teaching for many years. While adopting the new teaching and learning methodology, the teachers have to overcome many challenges. In this study, the teachers indicated the perceived level of seriousness of a number of typical problems of online teaching. The problems ranged from dealing with maintaining learners' motivation and engagement to teacher's access to technology. The results are relatively in line with the previous literature, indicating common challenges that online teachers are faced with (Nugroho, Ilmiani, \& Rekha, 2020). Although the teachers shared similar problems in online teaching, it is worth noting that the level of seriousness of these problems is not high. Some typical problems of online teaching, such as learner retention, the time commitment for online teaching and teachers' technology competence, were not perceived as being very serious in this study. It is possible that, having some previous online teaching experience, most of the participants in this study were better prepared for online teaching than most, despite the sudden shift to online teaching caused by the pandemic. Teachers' readiness for online teaching is likely to help them deal with problems more effectively and with more confidence. This explanation, of course, needs further investigation. 
Comparing the effectiveness of online and onsite teaching, the participants in this study were asked to focus on the five aspects of course content, pedagogical approaches, interactivity, assessment, and learners' performance. The results of this study relatively support the previous literature (Elfaki et al., 2019), as the participants tended to perceive online teaching as being equally effective as traditional classroom education. In fact, onsite and online teaching share many qualities. Learners are still required to attend class, physically or virtually, learn the material, and complete assignments, while teachers still have to design curricula, enhance instructional quality, answer class questions, motivate students to learn, and grade assignments (Paul \& Jefferson, 2019).

In this study, the participants perceived the course content of online courses to be as effective as in the traditional classroom. The result to some extent supports the existing literature in that, although there are some minor differences, the quality of the course content is always important in both onsite and online teaching (Darkwa \& Antwi, 2021). According to online teaching experts, the development of interactive content and activities that engage learners to practice and extend their knowledge and skills has a greater emphasis in the online environment (Abrahamsson \& Lopez, 2021).

The transition to online teaching from a traditional classroom may challenge many teachers with regard to pedagogical approaches. Many experienced face-to-face teachers may find themselves novices in the new online environment. Teachers generally try to replicate previous pedagogical practices, and this replication generally cannot capitalize on the dynamic nature of a technologically enhanced teaching and learning environment (Butnaru, Nita, Anichiti, \& Brinza, 2021). In this study, it is reasonable that no more than half of the participants perceived their online teaching methods to be equally effective. In fact, effective online teachers need adequate training in pedagogical approaches to adapt to their new teaching environment.

With regard to interactivity, the result of the current study is in accordance with most previous research, indicating that interactions in online teaching are usually more challenging (Darkwa \& Antwi, 2021). Only 29.4\% of the participants perceived online interactivity as being equally effective as in the traditional classroom. Interactivity in online classes is defined as communication among learners, between learners and teachers, and between learners and course content. It is necessary to create a blend of all these types of interaction to improve motivation, satisfaction and achievement in online courses (Mahle, 2011).

Assessment is an integral part of the teaching and learning process. It is interesting that in this study, online assessment was perceived as being equally effective as assessment in the traditional classroom. It is natural that the quality of online instruction can be ensured through teachers' positive perception towards performance assessments. In the relatively new arena of online education, the assessment challenges are even greater. Some online education experts suggest that effective online assessment techniques can be based on the characteristics of traditional teaching and learning; however, online assessment generally requires a more ongoing, systematic approach than that used in traditional instruction (Abduh, 2021).

In this study, based on teachers' perceptions in regard to academic performance, online learners generally performed less effectively than those who participated in onsite learning. The result is relatively in accordance with some recent studies (Hurlbut, 2018; Spencer \& Temple, 2021) that reported that students enrolled in traditional classes generally received slightly higher grades and assignment scores than those who participated in their online equivalents. However, it is worth noting that although students performed better in traditional face-to-face formats, their overall perceptions of online courses were positive and displayed higher levels of preference toward instructional technologies.

The sudden shift to online teaching might be stressful for some teachers. Understanding their perceptions toward online teaching, particularly in relation to typical problems and the effectiveness of online teaching, is important to ensure the appropriate adjustment in their teaching. By making significant changes in their pedagogical approaches and adapting to technology, teachers are able to perform effectively.

\section{Conclusion}

Although online teaching and learning continues to grow rapidly, particularly due to the Covid-19 pandemic, it still remains at an early stage of development. Therefore it is necessary to consider teachers' perceptions towards online teaching to make the appropriate adjustments to improve online teaching quality. In this preliminary study, it appears that teachers have a relatively positive perception towards online teaching, although many typical problems of online teaching do present themselves and the effectiveness of online teaching does not always compare favorably with traditional classroom teaching. Online teaching is here and is highly likely here to stay and it will continue to improve. The transition from traditional face-to-face classrooms to online teaching can be successfully achieved and quality can be ensured so long as challenges and ways for improving online teaching and learning can be closely examined.

\section{References}

Abduh, M. (202 1). Full-time online assessment during Covid-19 lockdown: EFL teachers' perceptions. Asian EFL Journal, $28(1)$, 26-46.

Abrahamsson, S., \& Lopez, M. D. (2021). Comparison of online learning designs during the Covid-19 pandemic within bioinformatics courses in higher education. Bioinformatics, 17(1), 9-15.Available at: https://doi.org/10.1093/bioinformatics/btab304.

Albrahim, F. A. (2020). Online teaching skills and competencies. Turkish Online Journal of Educational Technology, 9(1), 9-20.

Alsaaty, F. M., Carter, E., Abrahams, D., \& Alshameri, F. (2016). Traditional versus online learning in institutions of higher education: Minority business students' perceptions. Business and Management Research, 5(2), 31-41.Available at: http://dx.doi.org/10.5430/bmr.v5n2p31.

Baldwin, S. J., \& Trespalacios, J. (2017). Evaluation instruments and good practices in online education. Online Learning; 21(2), 1-18.Available at: http://doi.org/10.24059/olj.v21i2.913

Bawa, P. (2016). Retention in online courses: Exploring issues and solutions - A literature review. SAGE Open, 6(1), 1-11.Available at: https://doi.org/10.1177/2158244015621777.

Butnaru, G. I., Nita, V., Anichiti, A., \& Brinza, G. (2021). The effectiveness of online education during covid-19 pandemic - a comparative analysis between the perceptions of academic students and high school students from Romania. Sustainability, 13(9), 5311.Available at: https://doi.org/10.3390/su13095311.

Chiu, T. K. F., Lin, T. J., \& Lonka, K. (2021). Motivating online learning: The challenges of Covid-19 and beyond. Asia-Pacific Education Researcher, 30(1), 187-190.Available at: https://doi.org/10.1007/s40299-02 1-00566-w. 
Darkwa, B. F., \& Antwi, S. (2021). From classroom to online: Comparing the effectiveness and student academic performance of classroom learning and online learning. Open Access Library Journal, o8(7), 1-22.Available at: https://doi.org/10.4236/oalib.1 107597.

Efriana, L. (2021). Problems of online learning during Covid-19 pandemic in EFL classroom and the solution. Journal of English Language Teaching and Literature, 2(1), 38-47.

Elfaki, N. K., Abdulraheem, I., \& Abdulrahim, R. (2019). Impact of e-learning vs traditional learning on student's performance and attitude. International Journal of Medical Research \&' Health Sciences, 8(10), 76-82.

Gay, I. R., Mills, G. E., \& Airasian, P. (2012). Educational research: Competencies for analysis and application (10th ed.). US: Pearson Education.

Ho, N. Q. (2021). The challenges and opportunities of online learning during covid-19 pandemic. Journal of Science, 11(1), 3-14.

Hurlbut, A. R. (2018). Online vs. traditional learning in teacher education: A comparison of student progress. American Journal of Distance Education, 32(4), 248-266.Available at: https://doi.org/10.1080/08923647.2018.1509265.

Jensen, L. X., Bearman, M., \& Boud, D. (2021). Understanding feedback in online learning-A critical review and metaphor analysis. Computers \& Education, 173, 104271.Available at: https://doi.org/10.1016/j.compedu.202 1.104271.

Lathifah, Z. K., Helmanto, F., \& Maryani, N. (2020). The practice of effective classroom management in COVID-19 time. International Journal of Advanced Science and Technology, 29(7), 3263-3271.

Mahle, M. (2011). Effects of interactivity on student achievement and motivation in distance education. Quarterly Review of Distance Education, 12(3), 207-216.

Nugroho, A., Ilmiani, D., \& Rekha, A. (2020). EFL teachers' challenges and insights of online teaching amidst global pandemic. Journal of English Language Literature and Teaching, 4(3), 277-291.Available at: https://doi.org/10.3 1002/metathesis.v4i3.3195.

Orellana, A. (2006). Class size and interaction in online courses. The Quarterly Review of Distance Education, 7(3), $229-248$.

Paul, J., \& Jefferson, F. (2019). A comparative analysis of student performance in an online vs. face-to-face environmental science course from 2009 to 2016. Frontiers in Computer Science, 12(11), 1-9.Available at: https://doi.org/10.3389/fcomp.2019.00007.

Pham, H. H., \& Ho, T. H. T. (2020). Toward a 'new normal' with e-learning in Vietnamese higher education during the post Covid-19 pandemic. Higher Education Research \& Development, 39(7), 1327-1331.Available at: https://doi.org/10.1080/07294360.2020.1823945.

Rachmah, N. (2020). Effectiveness of online vs offline classes for EFL classroom: A study case in a higher education. Journal of English Teaching, Applied Linguistics and Literatures, 3(1), 19-26.Available at: http://dx.doi.org/10.20527/jetall.v3i1.7703.

Scherer, R., Howard, S. K., Tondeur, J., \& Siddiq, F. (202 1). Profiling teachers' readiness for online teaching and learning in higher education: Who's ready? Computers in Human Behavior, 118, 106675.Available at: https://doi.org/10.1016/j.chb.2020.106675.

Spencer, D., \& Temple, T. (2021). Examining students' online course perceptions and comparing student performance outcomes in online and face-to-face classrooms. Online Learning, 25(2), 233-261.Available at: https://doi.org/10.24059/olj.v25i2.2227.

Statista. (2020). Online learning problems faced by children during the COVID-19 pandemic in Vietnam as of April 2020 . Retrieved from https://www.statista.com/statistics/1190894/vietnam-online-learning-problems-for-children-during-covid-19-pandemic/.

Suleman, Q., \& Hussain, I. (2016). Effects of eclectic learning approach on students' academic achievement and retention in English at elementary level. Journal of Education and Practice, 7(16), 32-37.

Weizheng, Z. (2019). Teacher-student interaction in EFL classroom in China: Communication accommodation theory perspective. English Language Teaching, 12(12), 99-111.Available at: https://doi.org/10.5539/elt.v12n12p99.

Winter, E., Costello, A., O’Brien, M., \& Hickey, G. (2021). Teachers' use of technology and the impact of Covid-19. Irish Educational Studies, $40(2), 1-12$. 